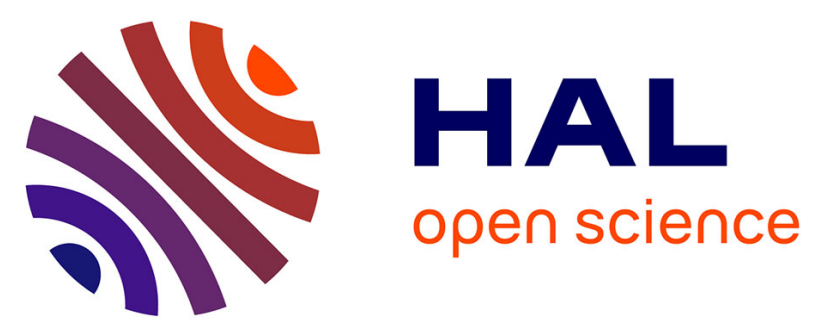

\title{
Analysis of Soil Water Wetting and Dynamics in Trace Quantity Irrigation
}

Haobo Cui, Shumei Ren, Peiling Yang, Huang Lingmiao, Zixuan Ma, Xiaorui Zhang, Weishu Wang, Zelin Li

\section{To cite this version:}

Haobo Cui, Shumei Ren, Peiling Yang, Huang Lingmiao, Zixuan Ma, et al.. Analysis of Soil Water Wetting and Dynamics in Trace Quantity Irrigation. 8th International Conference on Computer and Computing Technologies in Agriculture (CCTA), Sep 2014, Beijing, China. pp.489-494, 10.1007/9783-319-19620-6_55. hal-01420264

\section{HAL Id: hal-01420264 https://hal.inria.fr/hal-01420264}

Submitted on 20 Dec 2016

HAL is a multi-disciplinary open access archive for the deposit and dissemination of scientific research documents, whether they are published or not. The documents may come from teaching and research institutions in France or abroad, or from public or private research centers.
L'archive ouverte pluridisciplinaire HAL, est destinée au dépôt et à la diffusion de documents scientifiques de niveau recherche, publiés ou non, émanant des établissements d'enseignement et de recherche français ou étrangers, des laboratoires publics ou privés.

\section{(c)(1)}

Distributed under a Creative Commons Attribution| 4.0 International License 


\title{
Analysis of soil water wetting and dynamics in trace quantity irrigation
}

\author{
Haobo Cui ${ }^{1, \text { a }}$, Shumei Ren ${ }^{1, \mathrm{~b}}$, Peiling Yang ${ }^{2}$,Huang Lingmiao ${ }^{3}$,Zixuan $\mathrm{Ma}^{4}$,Xiaorui \\ Zhang ${ }^{5}$,Weishu Wang ${ }^{6}$, Zelin $\mathrm{Li}^{7}$ \\ ${ }^{1}$ College of Water Resources \& Civil Engineering, China Agricultural University, Beijing \\ 100083, China \\ ayinhexizhan@163.com, ${ }^{\mathrm{b}}$ renshumei@126.com
}

\begin{abstract}
Compared with ordinary subsurface drip irrigation the trace quantity irrigation has some new features which will provide water according to the demand of the crops and continuous supply right and small amount water to the root of crops slowly,so the flow and moisture distribution is different from others and this Soil box experiments was used to study it.the result shows that when the trace quantity irrigation tape was buried into the soil the flow is approximately $53 \%$ of it in the air and the moisture distribution is divided into three kinds according to the depth.
\end{abstract}

Keywords: trace quantity irrigation; flow; moisture distribution

\section{Introduction}

In order to improve the efficiency of water use in agricultural irrigation, we shall do some further research on the basis of existing water saving irrigation techniques to promote water conservation and the development of agriculture.Underground drip irrigation technology is a high efficient and water saving irrigation technique on the basis of the development of the drip irrigation technology ${ }^{[1]}$.

Trace quantity irrigation technology is the perfection of the underground drip irrigation technology which is increasingly mature,making the quantity of irrigation close to the actual amount of water that the plants need as far as possible is the key word to minimize the invalid evaporation ${ }^{[2]}$. The underground drip irrigation technology has greatly reduced the evaporation and the using of the high frequency of micro-irrigation technology will further reduce the quantity of it, on the premise of that high frequency will ensure the growth of crop, try to make the supply of water exactly equal to the quantity that absorbed by roots during the corresponding period of time.Theoretically,uninterrupted flow is demanded during whole life cycle of crop, if we can supply the flow to root zone along with the change of the requirements of different times that will has a certain extent reduce of evaporation. Based on the above ideas and trace quantity irrigation is developed based on soil capillary force principle and membrane filtration technology which will supply continuous, slowly amount of water to the crops ${ }^{[3,4]}$. 


\section{Experiments and Methods}

Soil box size is $1.2 \mathrm{~m} \times 0.8 \mathrm{~m} \times 0.6 \mathrm{~m}$, emitters spacing are $30 \mathrm{~cm}$, arranged four emitters, the two sides emitters are $15 \mathrm{~cm}$ from the box edge.

Before buried trace quantity irrigation tape into the soil, conducted background value measurement, using soil auger which diameter is $3 \mathrm{~cm}$ to take soil in the box, Randomly selected three points, one point take six layers are 0-10, 10-20, 20-30, 30$40,40-50,50-60 \mathrm{~cm}$, the oven drying method used for determining soil moisture content. Soil moisture background value shown in Table 1.

Table 1. Background values of soil moisture content

\begin{tabular}{ccccccc}
\hline Depth/cm & $0-10$ & $10-20$ & $20-30$ & $30-40$ & $40-50$ & $50-60$ \\
\hline $\begin{array}{l}\text { Soil Moisture } \\
\text { Content } \%\end{array}$ & 5.77 & 6.17 & 8.09 & 9.17 & 6.96 & 9.39 \\
\hline
\end{tabular}

Using Markov Bottles to supply water, Markov bottles will be placed on a tripod, adjust the height, maintain 1 meter constant head to supply water for trace quantity irrigation tape. The trace quantity irrigation tape was buried $15 \mathrm{~cm}$ under the soi ${ }^{[5,6]}$.

Collecting sample during irrigation $1 \mathrm{~d}, 4 \mathrm{~d}, 10 \mathrm{~d}, 16 \mathrm{~d}$, respectively, using soil auger to get three points (three points are $5 \mathrm{~cm}, 12.5 \mathrm{~cm}$ and $25 \mathrm{~cm}$ away from the emitters), each point take $0-10,10-20,20-30,30-40,40-50,50-60 \mathrm{~cm}$ layers of soil, the first sample we collect from the end of trace quantity irrigation tape.

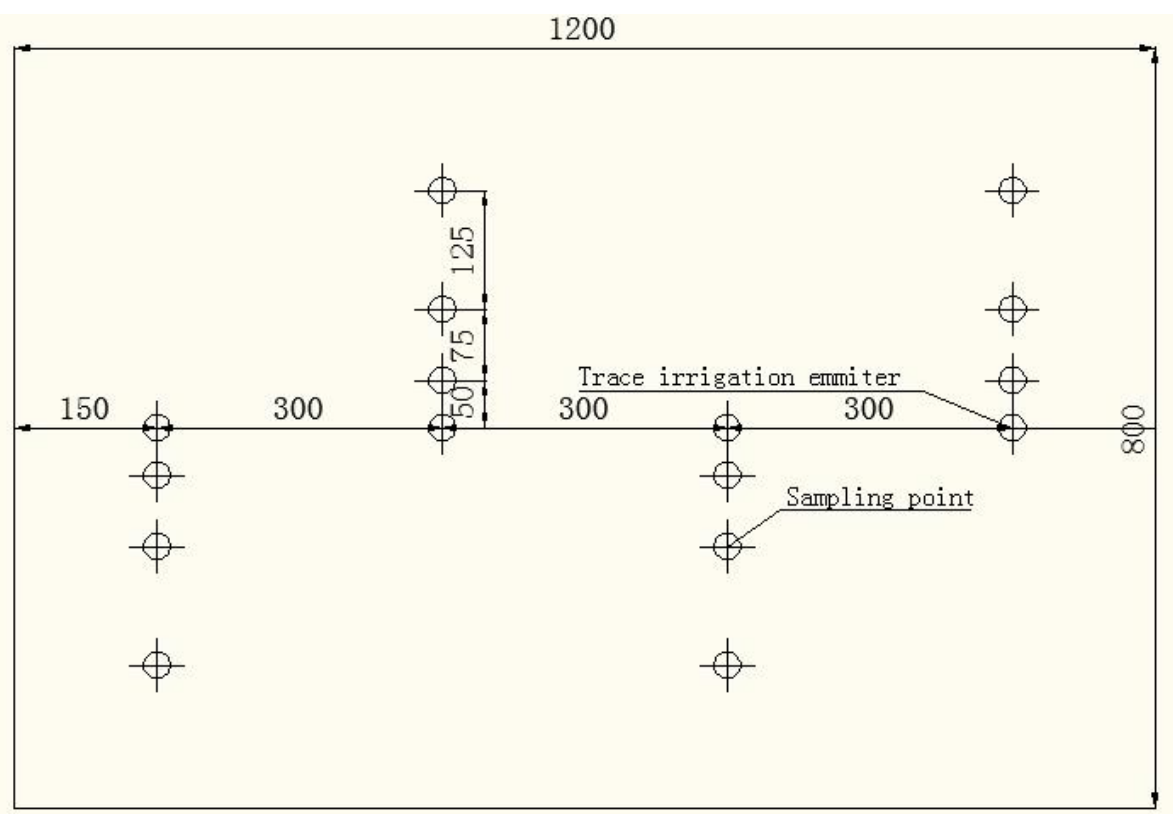

Fig.1. Soil box floorplan and sampling points (unit: $\mathrm{mm}$ ) 


\section{Data analysis and discussion}

After continuous observation for 16 days, we regularly read Markov bottle readings, the single emitter flow amount is shown in the table below.

Before the experiment, we test the average flow of the four emitters in air under $1 \mathrm{~m}$ head, the average flow was $0.36 \mathrm{~L} / \mathrm{d}$.

Table 2. Single emitter flow amount

\begin{tabular}{cccc}
\hline Date & Time & $\begin{array}{c}\text { Cumulative } \\
\text { flow amount } / \mathrm{L}\end{array}$ & $\begin{array}{c}\text { Average } \\
\text { flow amount } / \mathrm{L}\end{array}$ \\
\hline 13-Apr-14 & 4:50 PM & 0.078 & \\
13-Apr-14 & 5:39 PM & 0.2756 & \\
14-Apr-14 & 4:50 PM & 0.462 & 0.1864 \\
17-Apr-14 & 4:10 AM & 1.053 & 0.197 \\
19-Apr-14 & 5:00 PM & 1.5574 & 0.2522 \\
23-Apr-14 & 6:00 PM & 2.4076 & 0.21255 \\
24-Apr-14 & 3:13 PM & 2.5766 & 0.169 \\
27-Apr-14 & 3:40 PM & 3.08 & 0.1678 \\
29-Apr-14 & 4:00 PM & 3.4138 & 0.1669 \\
30-Apr-14 & 5:00 PM & 3.5646 & 0.1508 \\
\hline
\end{tabular}

During the experiment, We monitored the single emitter of trace quantity irrigation tape in the interval sampling time, the average daily flow amount showed a trend that first increase and then decrease, with soil gradually wetting. On April 14th, the average flow amount was $0.1864 \mathrm{~L} / \mathrm{d}$, then on April 19th, peaked at $0.2522 \mathrm{~L} / \mathrm{d}$, after that, rapidly decreased to $0.1508 \mathrm{~L} / \mathrm{d}$. The mean flow amount was $0.1935 \mathrm{~L} / \mathrm{d}$, approximately $53 \%$ flow amount in the air.

We took four times soil samples during the experiment, measured three points (three points are $5 \mathrm{~cm}, 12.5 \mathrm{~cm}$ and $25 \mathrm{~cm}$ away from the emitters),each point take $0-10,10-20,20-30,30-40,40-50,50-60 \mathrm{~cm}$ layers of soil, then draw line chart of soil moisture charge with layers by Excel, shown in Fig.2 (a, b, c, d, are 10-20, 20-30, 40-50, 50-60line chart, respectively). 


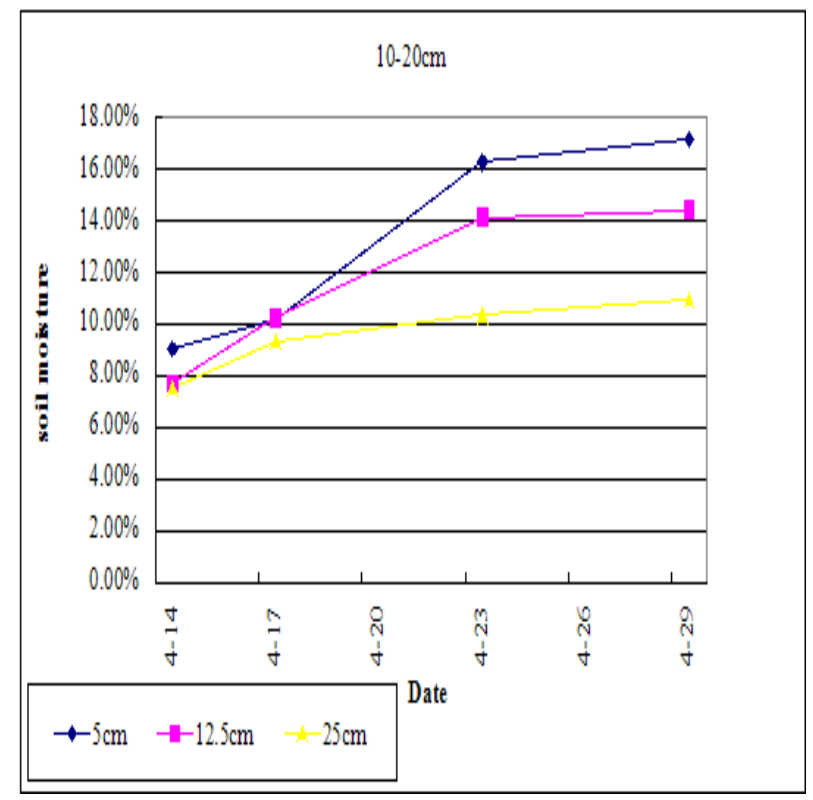

(a)

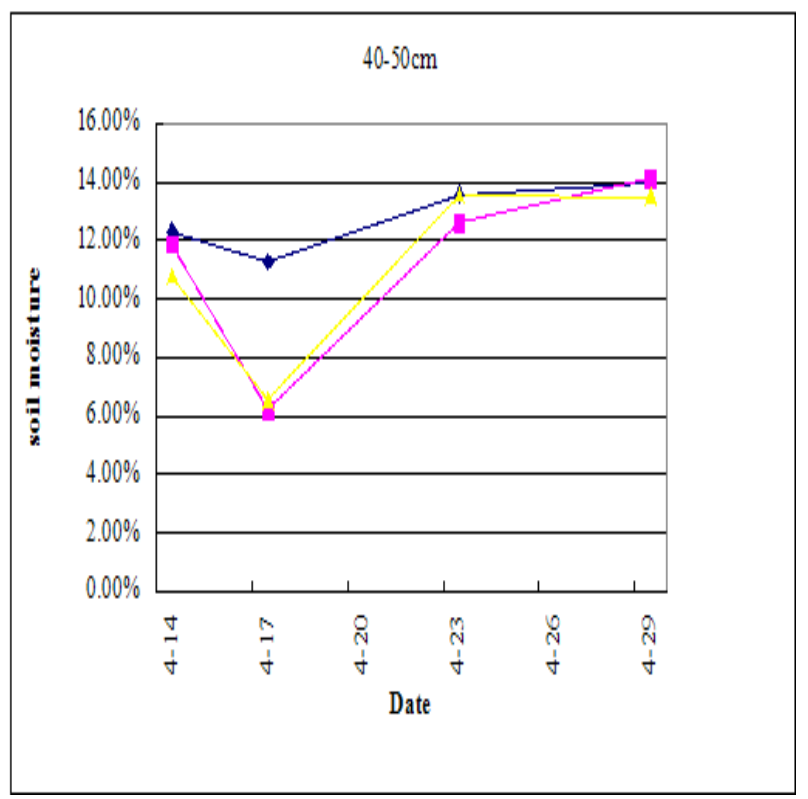

(c)

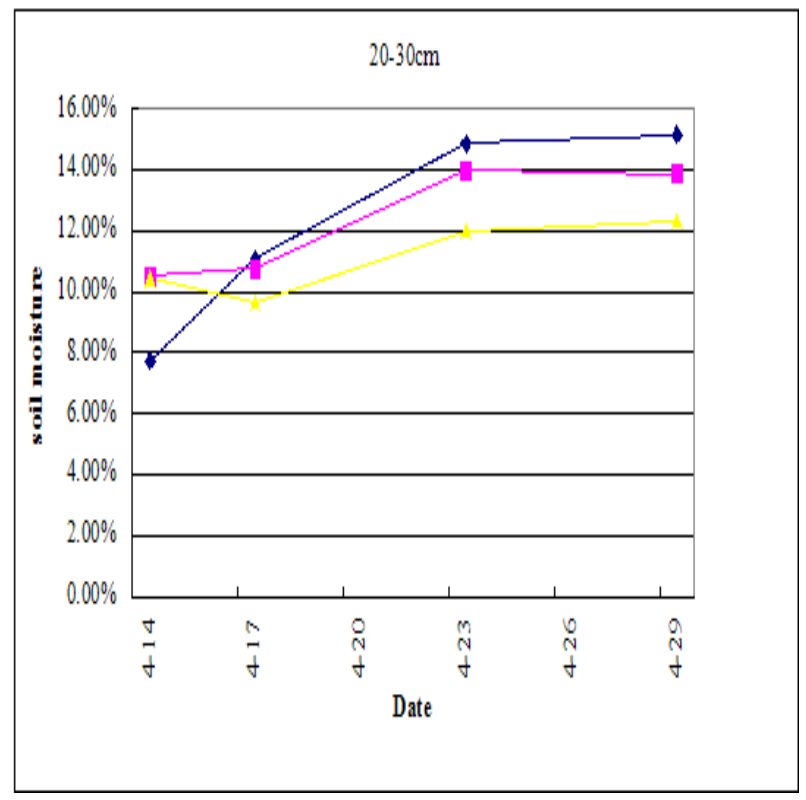

(b)

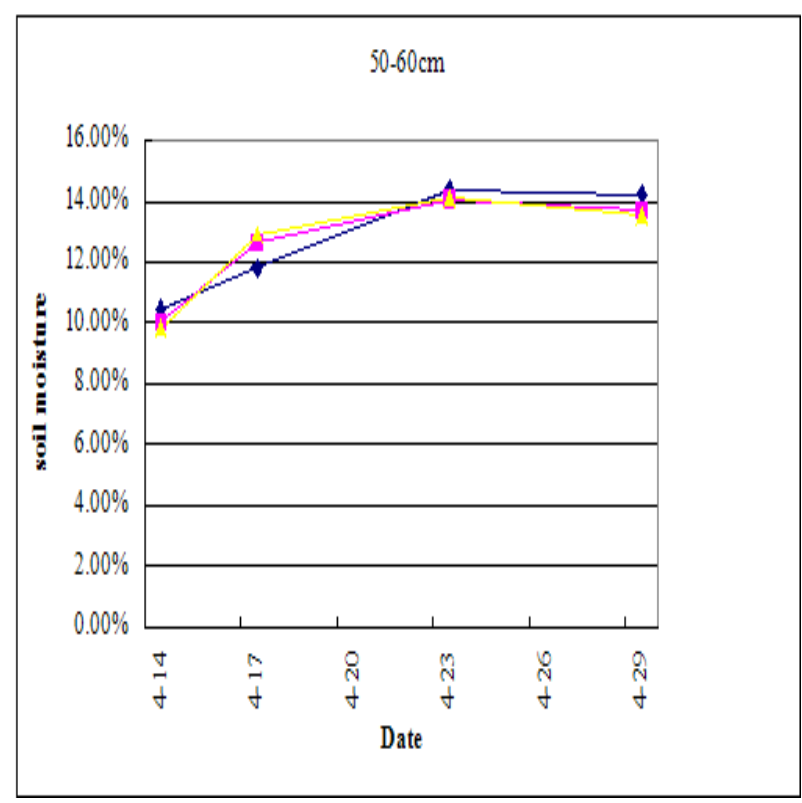

(d)

Fig.2. line chart of soil moisture charge with layers 
Fig.2 indicated that the the trend of moisture content with the distant to the surface of the soil change. Analysis of the problem from the perspective of the wet area horizontal propagation to observe the change of moisture content, whether it is $5 \mathrm{~cm}, 12.5 \mathrm{~cm}$ or $25 \mathrm{~cm}$ away from the emitters, the soil moisture content is gradually increasing with time at $10-20 \mathrm{~cm}$, and when the area is nearer to the emitters the moisture content increased faster,after 10 days' experiment this trend begin to slow down and at the following 6 days' experiment the increased of moisture content is $15 \%$ of it increased at the beginning of the 10 days' experiment.To compared with $10-20 \mathrm{~cm}$ that the trend of increased at $20-30 \mathrm{~cm}$ is slow down and even appeared to reduce,this phenomenon is sharped in the region of the 40 to $50 \mathrm{~cm}$ away from the surface of the soil, after 3 days' experiment at the beginning the moisture content fell down from $11 \%$ to $6 \%$.This situation has changed at $50-60 \mathrm{~cm}$, soil moisture content in this region has a slowly increased at the fist and then tended to be stable, this process makes the soil moisture content rise $2 \%$ and this amount is $25 \%$ of the soil moisture content increased at $10-20 \mathrm{~cm}$ only.

\section{Results and conclusion}

Compared with ordinary subsurface drip irrigation the amounts of flow is small and when the emitters buried in the soil the flow amount is about 53\% in the air, while the experiment demonstrated that under $1 \mathrm{~m}$ head only, but the biggest characteristic of trace quantity irrigation is to use soil capillary force and supply water according to crop demand, if we increase the head to pursuit the flow only that is equivalent to give up this feature, but how is the crop growth under the condition of water absorbing and should we need appropriately add head still need further studies.

Due to the flow amount is very few and soil surface evaporation makes that even in the condition of trace quantity irrigation the soil moisture content growing slowly even has a reduce trend in the beginning of 3 to 5 days, but this is most important period to the germination of seeds,in order to make the seeds germinate well we shall let the trace quantity irrigation emitters closely to the surface of soil as far as possible, but the most suitable distance still needs further research.

\section{Acknowledgements}

We are grateful for the financial support from the National Science and Technology Ministry (ID: 2014BAD12B06), the Natural Science Fund of China (No. 51179190), Appreciation is also extended to Dr. Jin jishi for equipment installation. 


\section{References}

1. Wu feng, Li wangcheng, Li jinshan, Fan yongshen, Feng junjie. Experimental study on hydraulic characteristics of subsurface drip irrigation emitter[J]. Transactions of th e CSAE, 2003,19(2):85-88.

2. Yuan Qiaoxia, Zhu Duanwei, Ai Ping, et, al. Current Situation and Developing Trend of Subsurface Irrigation Technology in Protected Land Cultivation[J]. Transactions of the Chinese Society of Agricultural Machinery, 2006, 37(9): 199-203.

3. Zhu Jun, Jin Jishi, Yang Chunxiang. Effects of trance quantity irrigation on yield, dry matter portioning and water use efficiency of spherical fennel grown in greenhouse[J].Journal of Drainage and Irrigation Machinery Engineering, 2014, 32(4): 338-342.

4. Yang Mingyu, An Shunwei, Zhou Jihua, et, al.Effects of Different Trace Irrigation Pipe Depths on Eggplant Growth, Yield and Water Utilization Efficiency in Solar Greenhouse[J].China Vegetables,2012,20:78-82.

5. An Shunwei, Zhou Jihua, Liu Baowen, et, al. Effects of different fertilizing amount on yield and fruit quality of Pimento under trace irrigation[J]. Zhongguo Yuanyi Wenzhai, 2013, (4):17-18.

6. Chen Xinming, Cai Huanjie, Shan Zhijie, et, al. Yield and Quality of Tomato and Cucumber under Non-Pressure Subsurface Drip Irrigation at Crop Root Zone[J]. Acta Pedologica Sinica, 2006, 43(3):486-492. 